\title{
Populismo e neopopulismo na América Latina: o seu legado nos partidos e na cultura política
}

\author{
Marcello Baquero \\ Ph.D em Ciência Política (Florida State University) \\ Professor da Universidade Federal do Rio Grande do Sul \\ Porto Alegre, Brasil \\ nupesal@yahoo.com
}

\begin{abstract}
Resumo Nas democracias latino-americanas estão emergindo fenômenos que se supunham ter desaparecido em virtude do surgimento das chamadas sociedades pós-modernas. Um desses elementos é o neopopulismo, sobre o qual continuam a existir divergências a respeito de sua conceitualização e impacto no processo democrático. Este artigo tem como objetivo analisar o neopopulismo, avaliando sua origem e evolução, o impacto nos partidos políticos e o tipo de cultura política que se constitui quando essa práxis política está presente. O estudo, de caráter descritivo-empírico, utiliza dados de pesquisa tipo survey realizada em 2005, em três capitais latino-americanas, com amostras probabilísticas. Os resultados apontam para a presença de predisposições favoráveis dos cidadãos às figuras politicamente populares em detrimento das instituições. Sugeremse, como conclusão, alguns dispositivos que poderiam se constituir em caminhos alternativos para fortalecer uma cultura política participativa e fiscalizadora dos gestores públicos, valorizando as instâncias de mediação política convencional.
\end{abstract}

Palavras-chave: neopopulismo, América Latina, partidos, democracia, cultura política.

\section{Introdução}

\begin{abstract}
A pesar de as Ciências Sociais terem declarado o fim do populisA mo na era da globalização e do pós-modernismo, esse fenômeno continua vigente sob novas ou não tão novas roupagens, comprometendo o fortalecimento democrático na América Latina. Desse modo, questões que eram centrais num passado recente continuam a ser proeminentes nas discussões sobre a democracia contemporânea.

Nos últimos anos, por exemplo, tem se constatado uma perda de representatividade da expressão social e, por consequência, a materialização da irrelevância do campo político para a maioria dos cidadãos, o que limita sua vontade de participar, via instituições formais, da vida política. Ao mesmo tempo, tal situação resulta numa tendência de recolhimento para o privado, haja vista a não existência de fontes de construção de identidades coletivas com base na solidariedade e em valores objetivos universais. O cidadão individualista e egoísta, portanto, renega a política na sua dimensão formal, embora dela participe. Seu comportamento político, nessas circunstâncias, se mostra favorável a aceitar campos privados de negociação com indivíduos e não com instituições. Esse é o caso do neopopulismo contemporâneo.
\end{abstract}


Assim, a América Latina continua a desafiar os cientistas sociais a encontrar explicações para fenômenos dessa natureza, exigindo análises sob perspectivas diferentes dos pesquisadores. Muitos deles, inebriados pelo aporte teórico do neoinstitucionalismo, concluíram, equivocadamente, que a consolidação da democracia no continente estava plasmada em análises sobre os desempenhos institucionais.

Presentemente, sabe-se que, embora as instituições sejam imprescindíveis nas estratégias políticas dos atores, não é razoável supor que o simples funcionamento delas possa garantir a continuidade e a normalidade da democracia, uma vez que continua a persistir a desigualdade social. Por exemplo, se o mercado é considerado o lócus de fazer política na vida moderna, abrangendo todo o cenário social, a disputa pelo poder passa a ocorrer entre as elites que utilizam as próprias regras do mercado para alcançar seus objetivos, negligenciando totalmente a sociedade civil e abrindo caminho para fenômenos tais como o clientelismo, a corrupção e, atualmente, o neopopulismo. $\mathrm{O}$ resultado provoca o desencanto, a indiferença e a desconfiança das pessoas, que não reconhecem na política o terreno adequado e natural do exercício de sua cidadania.

Apesar dessa situação, o neoinstitucionalismo, associado aos critérios operacionais estabelecidos por Dahl (1997), fizeram com que pesquisadores na área de política comparada na América Latina voltassem sua atenção para características institucionais, como a forma de governo (Linz; Valenzuela, 1994) e a institucionalização dos sistemas partidários (Mainwaring; Scully, 1995), em detrimento de outras dimensões, entre as quais a dimensão normativa da democracia.

O fato é que o mistério democrático, como bem nos lembra Rouquié (1985), continua a nos rondar e a nos estimular intelectualmente. Um desses mistérios é o reaparecimento do neopopulismo na época da terceira onda democrática (Huntington, 1991), que tem ocorrido apesar da existência de uma poliarquia formal eficiente, de avanços econômicos, e de discursos cartesianos para superá-lo. Desse modo, não só compromete a moldura institucional, mas, sobretudo, obstaculiza a participação política cidadã que se pauta por comportamentos à margem de certa racionalidade esperada na qual é imperativo que a mediação institucional entre Estado e sociedade seja eficiente e considerada legítima pela população.

A presença desse fenômeno político se explica em parte pela incapacidade das instituições poliárquicas modernas em proporcionar, além de uma estabilidade formal, um bem-estar social e econômico para a maioria da população. Tal situação produz subculturas com uma consciência social precária que as vulnerabiliza a discursos demagógicos e de manipulação de líderes populares.
Esse contexto possibilita que líderes neopopulistas rompam com o marco institucional poliárquico, defendendo e desenvolvendo uma práxis política com base em ações e discursos fortemente ancorados no líder político. O pacto social, nesse cenário, não é respeitado: tais formas de alcançar o poder dependem mais consistentemente dos votos e apoio das classes populares - chamadas, presentemente, de setores subalternos - em detrimento das classes média e alta.

A questão que se coloca, então, na pauta do processo de construção democrática é: como os novos governos têm sucesso no estabelecimento de gestões públicas que colocam as instituições da democracia representativa em segundo plano? $\mathrm{Na}$ tentativa de responder a essa questão, este trabalho pretende examinar os elementos que ajudam a manter governos (neo)populistas no poder numa época caracterizada como pós-moderna ou pós-materialista. $\mathrm{O}$ trabalho está estruturado em três partes: a primeira examina a origem e a evolução do populismo desembocando no neopopulismo; a segunda parte analisa o impacto de neopopulismo nos partidos políticos; e a terceira parte avalia, empiricamente, aspectos da cultura política associados ao fenômeno do neopopulismo. Os dados empíricos utilizados provêm principalmente de pesquisa tipo survey realizada em 2005 em três cidades latino-americanas: Porto Alegre (Brasil), Montevidéu (Uruguai) e Santiago do Chile (Chile), com amostras representativas probabilísticas de 500 entrevistas em cada cidade (Nupesal, 2005).

$\mathrm{O}$ argumento central deste trabalho é de que o apoio das classes majoritárias aos líderes políticos, em detrimento das instituições políticas, radica em predisposições atitudinais e comportamentos influenciados por variáveis de caráter estrutural, que promovem o personalismo, o particularismo e práticas clientelísticas que fomentam o fenômeno (neo)populista. A versão moderna do populismo, em nossa opinião, é uma réplica daquilo que Faletto (1982, p. 72) identificou há mais de duas décadas como um populismo participativo: "o populismo continua a ser, apesar de todos seus vícios, a grande experiência de participação política popular". Assim, não se trata de avaliar se o populismo pertence ou não ao passado, mas de compreender sua presença contemporânea no processo de construção democrática da América Latina, fazendo uma retrospectiva sobre sua origem, evolução e conceituação.

\section{O populismo e o neopopulismo}

O termo "populismo", como conceito teórico, é um dos temas mais polêmicos da ciência política latino-americana. Nas décadas de 1930 e 1950, produziu-se no panorama político da América Lati- 
na uma mudança significativa no que diz respeito às orientações políticas dos governos da época. Surgia, nesse período, uma nova modalidade de governo o populismo. Na virada do milênio, esse fenômeno reaparece e passa a ser denominado neopopulismo.

Alguns autores continuam a insistir em definir o populismo em termos de sua base social e econômica de apoio, enquanto outros enfatizam seu conteúdo ideológico ou estratégia de discurso. Entretanto, o fato é que o termo "populismo" tem sido aplicado a um amplo conjunto de líderes e movimentos, enquanto alguns autores questionam se o populismo é realmente um fenômeno único e distinto.

Isto pode ser atribuído ao fato de que o conceito sobre populismo não é novo, nem teve sua gênese nos países latino-americanos (o que em parte explica a controvérsia sobre seu significado). O termo já era utilizado nos Estados Unidos, no século XVII, para caracterizar a preocupação dos pequenos comerciantes rurais da época com as crises geradas pelo sistema monetário.

O termo "populismo" também foi utilizado para identificar certos movimentos políticos, e até certos tipos contemporâneos de Estado, no chamado "Terceiro Mundo". Deve-se ressaltar que, nos últimos anos, o termo "neopopulismo" também tem sido empregado para caracterizar partidos ou movimentos políticos que operam dentro dos marcos de uma poliarquia e economia de mercado, gerando aquilo que Roberts (1995) chama de um novo paradoxo, qual seja o surgimento de líderes personalistas que seguem políticas neoliberais e, paradoxalmente, contam com o apoio amplo da população.

Numa retrospectiva histórica conceitual sobre o populismo na América Latina, estudos revelam divergências em relação ao seu significado. Por exemplo, Weffort (1978) considera o populismo como uma ideologia da pequena burguesia. Já para Saes (1976), o populismo é visto como a ideologia das camadas médias urbanas. Outros estudiosos têm analisado o populismo em termos de situação social, estrutura social e superestrutura ideológica. A ênfase nesses últimos aspectos caracterizaria o que Little (1975) denomina "abordagem estrutural". Também vem sendo caracterizado como um movimento político, como uma síndrome, como uma resposta às crises do desenvolvimento e como sinônimo de nacionalismo. Igualmente, o termo "populismo" tem sido aplicado a um conjunto diverso de situações contextuais, a partir de múltiplas perspectivas teóricas: a perspectiva histórico-sociológica (Germani; Di Tella; Ianni, 1973), a perspectiva econômica (Dornbusch; Edwards, 1991), a perspectiva ideológica (Laclau, 1977) e a perspectiva política (Franco; Cotler; Rochabrún, 1991). Nas duas últimas décadas, o neopopulismo tem sido associado a líderes populares que relegam o Legislativo a um segundo plano, lançando mão de medidas provisórias e decretos-leis para governar.

Um fator de discordância entre as várias correntes teóricas que estudam esse fenômeno político é o papel que as massas desempenham dentro desse movimento. Por um lado, de acordo com Debert (1979), o termo "populismo", tanto na linguagem popular como em análises científicas, é utilizado para expressar o fenômeno da emergência de classes populares na vida política. Por outro lado, Smith (1978) argumenta que o ingresso das massas na vida política durante o período populista era meramente instrumental. A divergência de interpretações com relação ao papel das massas no cenário político levou o Estado populista brasileiro, de acordo com Saes (1976, p. 32), a criar "um mecanismo simultâneo de integração e manipulação da classe operária”. Essa ambiguidade, continua Saes, "não deve, no entanto, ser considerada como uma anomalia, mas como uma essência e, ao mesmo tempo, a contradição fundamental do populismo".

Dos argumentos acima citados deduz-se que o populismo, como forma de governo, caracteriza-se muito mais pelo seu caráter manipulativo, no qual a ingerência "efetiva" das massas no processo decisório do Estado está, na prática, sempre fora de consideração, ou tem um caráter puramente simbólico e manipulativo. Nas condições atuais, o neopopulismo trabalha com um clientelismo de massas via políticas públicas de caráter assistencialista. $\mathrm{O}$ apoio da população continua a se centrar nos chamados setores subalternos e/ou nas classes populares. Tal distinção visa demonstrar uma diferença de caráter estrutural entre populismo e neopopulismo. Está além dos objetivos deste artigo polemizar tal diferenciação conceitual, mas acreditamos que a mudança de nomenclatura retórica não retrata o que realmente ocorre em nossos países; ou seja, as classes ou setores subalternos continuam a ser os mesmos que historicamente foram excluídos das políticas públicas e se constituem em massa de manobra de líderes que buscam o poder político.

Ao contrário do que ocorreu na Europa e nos Estados Unidos, comenta Di Tella (1974), na América Latina não se produziram movimentos de mudança social com base nas classes médias através de um partido liberal, ou por um movimento operário com base em sindicato, mas surgiu uma variedade de movimentos políticos que, na ausência de um melhor termo, foi denominada "populismo".

Um dos elementos que favoreceram a emergência de movimentos populistas nessas nações foram as precárias condições estruturais, de ordem econômico-social. Os líderes populistas capitalizaram, habilmente, as crises econômicas, desenvolvendo um discurso político que "sensibilizava" as massas, empregando, inclusive, alguns dos símbolos e retóricas usados pelos fascistas durante os anos 1930. Essa situa- 
ção prevalece nos dias atuais, pois a situação econômica da maioria da população latino-americana continua a ser precária, mantendo as condições para que um discurso popular se consolide.

Poucos temas são, desse modo, mais centrais para a análise das democracias modernas do que a compreensão da influência das desigualdades econômicas na manutenção de traços e práxis tradicionais na política. As disparidades sociais e econômicas criam um potencial de geração de conflitos entre o que Tocqueville (1998), no século XIX, identificava como os que têm e os que não têm. Nessas circunstâncias, há uma percepção hegemônica na opinião pública de que o governo e as instituições políticas não são merecedores de confiança por sua incapacidade de processar as demandas sociais. A percepção, por parte da maioria da população, de uma incapacidade institucional para resolver os problemas sociais produz, na prática, uma desinstitucionalização dos mecanismos de mediação política, vulnerabilizando os setores mais frágeis da população para apelos demagógicos e populistas.

Desse modo, a prática política do neopopulismo - da mesma maneira que o velho populismo - se orienta, na sua essência, pelas regras tradicionais de dominação político-econômica. Essa práxis política bloqueia o acesso de novos grupos e das massas ao poder. Por essa razão, pode-se dizer que o populismo e o neopopulismo são movimentos sem base firme em nenhuma classe social específica, mas dependem, para a sua sustentação política, do apoio de vários setores das mais variadas classes, sendo a classe popular urbana atualmente sua espinha dorsal.

Além dessas características, outros fatores podem ser apontados como vitais para que o neopopulismo surgisse com força na virada do milênio. Um deles foi a incapacidade (ou não desejo) dos partidos políticos tradicionais de se ajustarem a uma nova realidade econômica em evolução. Outro elemento crucial, e decorrente do anterior, foi a emergência de novos grupos influentes na sociedade que reivindicavam seu espaço político-econômico.

Pelo exposto, constata-se que os movimentos neopopulistas, de uma forma geral, superestimam a sua capacidade de conciliação e acomodação dos interesses divergentes. $\mathrm{Na}$ medida em que procuram atender todo e qualquer tipo de tensão social e política, acabam criando um governo de posicionamentos políticos híbridos e limitados, principalmente pela sua intenção exagerada de tentar resolver conflitos de natureza histórica, através de uma política de favoritismo e empreguismo. Nessas circunstâncias, constata-se que as alterações políticas de natureza estrutural não têm ocorrido como se esperava das novas democracias, na medida em que governos populares de "esquerda", têm continuado a utilizar mecanismos neoliberais quando no poder.
O que se pode afirmar é que, ao mesmo tempo em que os movimentos neopopulistas modernos se popularizam, as aspirações e expectativas das classes emergentes de conseguir uma mobilidade social relativamente rápida não se materializam. Configura-se, nesse contexto, um problema histórico das sociedades sob esse efeito, qual seja a incapacidade real de conciliar o processo de crescimento econômico com uma distribuição de renda mais adequada, capaz de satisfazer às reivindicações de grupos emergentes.

A habilidade dos líderes neopopulistas de cooptar grupos politicamente "ameaçadores" tira toda e qualquer possibilidade de sucesso de organizações secundárias para se organizar. Assim sendo, o líder neopopulista se transformou (e se transforma) num agente de organização das massas em detrimento de outras organizações, tais como os partidos políticos.

Leis (2008), por exemplo, na sua comparação entre o antigo populismo e o neopopulismo contemporâneo, argumenta que o primeiro não prejudicava a democracia com seu fracasso, enquanto o populismo na sua versão "neo" afeta negativamente as democracias. Segundo o autor, as promessas de solução imediata dos problemas do país implicam, quando da chegada do populismo ao governo, uma violência contra o sistema institucional estabelecido. Acrescenta ainda que a América do Sul registra uma presença cada vez mais forte do populismo e um consequente retrocesso político. Presentemente, no âmbito da América Latina, aponta-se Hugo Chávez como a materialização do populismo contemporâneo, junto com seus colegas Evo Morales, na Bolívia, e Rafael Correa, no Equador (Plattner, 2010).

Examinadas as características gerais dos movimentos populistas, passa-se, a seguir, a analisar as razões de sua influência negativa na evolução de partidos nas nações latino-americanas.

\section{Populismo e partidos políticos}

Uma forma de superar os vícios de práxis neopopulista é a de (re)institucionalizar a participação política mediada pelos partidos políticos. Pressupõe-se que os partidos modernos precisam ser fortalecidos na sua capacidade de canalizar os interesses da sociedade perante o Estado. A reinstitucionalização de mecanismos efetivos de mediação política poderá significar o fim de iniciativas (neo)populistas. Desse modo, o que necessita prevalecer é a ação coletiva mediada pelos partidos e não a participação coletiva anômala, que ocorre em governos personalistas.

O que precisa ser ressaltado é que a condição de precariedade econômica da maioria da população gera massas disponíveis que não atuam motivadas por 
interesses coletivos e, portanto, são facilmente manipuláveis por líderes "personalistas" e/ou "carismáticos". Ao mesmo tempo, é preciso enfatizar que esse comportamento massificado, considerado anômalo pelas ciências sociais, é, de fato, um comportamento racional em virtude das circunstâncias em que ocorre. Instituições formais de mediação política, quando ineficientes e combinadas com as condições econômicas precárias da população, geram relações sociais que operam por meio de redes clientelísticas, nas quais os eleitores trocam seu apoio eleitoral por favores e pela obtenção de serviços essenciais (Menéndez-Carrión, 1988).

Essa situação não é específica de uma determinada época, mas acreditamos, da mesma forma que Laclau (1977), que as práticas políticas geradas pela mobilização populista, longe de se constituírem numa mistura híbrida de tradição-modernidade que, espera-se, se esgote com o processo de globalização, na verdade se materializam numa especificidade da experiência popular de fazer política. Por essa razão, é fundamental tentar compreender como os cidadãos fazem política e como a decodificam, ou seja, como se constrói uma cultura política que gere mecanismos para o fortalecimento do neopopulismo.

O populismo começou como movimento popular e, ao mesmo tempo, manteve contradições internas e vícios políticos tradicionais. Os mecanismos empregados pelos líderes desses movimentos para conseguir o poder foram quase os mesmos utilizados para mantê-los nessa posição. Mobilizam os eleitores das camadas populares para desequilibrar "legalmente" as eleições, organizam passeatas em massa contra os seus oponentes. Fazem uso extensivo do clientelismo para recompensar seus seguidores e utilizam os recursos do Estado para promover o desenvolvimento econômico e estabelecer mediações entre empresários e empregados.

Esses elementos que se reproduzem no neopopulismo constrangem o desenvolvimento de uma cultura política participativa, ao mesmo tempo em que deslegitimam as instituições políticas, principalmente os partidos políticos. Igualmente, o neopopulismo, da mesma forma que o populismo tradicional, ao invés de incentivar a constituição de partidos bem-estruturados e que desfrutem de uma continuidade, gera movimentos sociais e políticos precariamente organizados. Prevalece, nesse contexto, uma práxis política que superdimensiona a instituição presidencial e não as organizações intermediárias que estabelecem as relações entre Estado e sociedade. Numa análise histórica se verifica que o populismo não incentivava a formação de partidos, visto que se considerava como um movimento apolítico, cuja tarefa essencial era a de restaurar a economia, através de um fervoroso nacionalismo. No presente, o neopopulis- mo opera cooptando os membros do Legislativo para alterar a Constituição com vistas a se manter no poder. Geralmente, o lema utilizado para dar legitimidade a essa prática política é o de recorrer à "política da antipolítica".

Assim, as eleições continuam a ser utilizadas como um instrumento para dar às massas a ideia de "estar participando" do processo político. Esse tipo de manipulação deteriora as possibilidades de surgimento de partidos políticos de oposição efetivos, na medida em que não só o populismo os despreza, mas as próprias massas não são atraídas por organizações partidárias alternativas, já que estas não têm nem estruturas sólidas, nem melhores "programas" que o populismo.

Outro elemento que contribuiu decisivamente para o sucesso dessa práxis política, em detrimento de partidos, foi o caráter carismático dos líderes, que habilmente utilizam esse elemento para consolidar e aumentar seu poder, para implementar suas estratégias político-econômicas e sociais e para manter, fora da arena política, partidos de oposição. Essa situação continua vigente na maioria dos países latino-americanos.

Igualmente não se deve esquecer de que o populismo tem uma forma de funcionamento que é de caráter corporativista. Subjacente ao corporativismo está a negação de qualquer organização (partido) fora das redes governamentais. Isto porque uma das características do populismo/corporativismo é a de que todo e qualquer interesse privado seja representado na política através de organizações ou instituições ordenadas hierarquicamente e controladas pelo Estado (Wynia, 1978).

Em regimes com essas características, os partidos políticos não são efetivos pela forma como o processo eleitoral é operacionalizado. Isto é, a força de um partido nas urnas não é determinada pela plataforma partidária, mas sim pela "popularidade dos líderes populistas". A utopia eleitoral dos líderes populistas, portanto, pode ser antecipada a priori, devido ao controle que estes exercem sobre as massas populares. Adicionem-se a esse aspecto o desapego e a desconfiança das pessoas nas instituições políticas.

Cabe ressaltar que, nas áreas urbanas, o clientelismo se manifesta de forma diferente; isto é, o próprio contexto operacional modifica a dinâmica do funcionamento das relações patrão-cliente. É sabido, por exemplo, que a maioria dos países da América Latina sofre de desemprego crônico. No entanto, quase todas as pessoas nessas áreas que têm idade para trabalhar ganham alguma coisa, por menos que seja. "Isto é possível graças a um corpo superabundante de empregos administrativos nas empresas públicas e privadas e também a uma política de inversão pública que permite empregar, na construção, a mão-de- 
-obra excedente de caráter manual" (Ionescu; Gellner, 1970, p. 46).

Analisado dessa forma, o neopopulismo é um movimento pragmático, caracterizado por uma ambiguidade ideológica, forçado a adotar ideias imediatistas, operacionalizadas e implantadas id eias na efetivação de objetivos em curto prazo.

Dos pontos já discutidos pode-se concluir que a experiência populista na América Latina tem demonstrado que, na medida em que "eliminou" o patrão tradicional (caudilho ou coronel), o próprio líder do movimento assumiu o papel do patrão, pelo menos até que a síndrome de dependência fosse superada (o que até hoje não se conseguiu). Em vez de eliminar completamente a dependência social numa relação paternalista, o populismo criou um patrão gigantesco - o Estado e sua burocracia -, produzindo o que alguns autores têm denominado "clientelismo de massas" (Andrade, 2005). Nesses tipos de governo, os partidos políticos não são autorizados a funcionar "normalmente", atrasando a sua evolução e aprendizado organizacional.

Mas como explicar a difusão e aceitação das ideias populistas nas sociedades latino-americanas? Principalmente de grupos que, teoricamente, seriam antagônicos a estes movimentos?

Di Tella $(1974$, p. 60), que analisa o populismo na América Latina, argumenta:

As massas têm nos países do Terceiro Mundo mais poder do que jamais tiveram na experiência europ eia, para um dado nível de desenvolvimento econômico. Por isso, aos setores superiores ou médios (ainda no caso de que sejam partidárias da reforma) torna-se necessário utilizar ideologias demagógicas; do contrário não poderão canalizar as massas a seu favor. A necessidade de uma ideologia se torna ainda mais aguda pelo fato de que não apenas é necessário integrar as massas, mas também os intelectuais, e alguns dos grupos incongruentes. Os estratos mais baixos das massas poderiam contentar-se com uma liderança personalizada, carismática, desde que a considerassem fortemente anti-imperialista ou antioligárquica. Porém, os outros grupos, em particular os intelectuais marginais ou subocupados, exigem um maior refinamento ideológico.

A partir desse argumento, o neopopulismo pode ser caracterizado como um movimento político, já que a própria ambiguidade ideológica é um fator de atração dos vários segmentos heterogêneos da sociedade, necessários para "legitimar" o governo. Mas, como querem resultados imediatos, ao invés de um desenvolvimento gradual e dentro de uma realidade latino-americana, os neopopulistas se vêem compelidos a utilizar medidas pragmáticas, consideradas ine- vitáveis em curto prazo, para a consecução de seus objetivos. A justificativa para esse tipo de comportamento tem sido buscada na analogia proposta por Weber (1999) sobre a ética da convicção, vis-à-vis a ética da responsabilidade, a qual permite que convicções (ideológicas) possam ser substituídas por um bem maior (o país), sem representar algum tipo de comprometimento ético ou moral. Com base nesse princípio, a convivência do neopopulismo com o neoliberalismo é considerada normal.

$\mathrm{Na}$ área política, como foi observado anteriormente, o pior de todos os males, no nosso entender, foi $\mathrm{o}$ aspecto negativo, em termos gerais, que o populismo, como forma de governo, exerceu na evolução dos partidos políticos. O modelo populista de desenvolvimento econômico deixou deliberadamente à margem do "processo de produção" a maior parte dos cidadãos que, de repente, se encontraram desorganizados e, mesmo no contexto urbano, forçados a recorrer às formas de reivindicação tradicionais - principalmente o clientelismo. Do mesmo modo, o neopopulismo eventualmente é viciado pelo próprio elemento que inicialmente procura combater - a corrupção. Assim, o neopopulismo, na América Latina, continua a evidenciar uma incongruência entre teoria, discurso e prática. Embora seja um movimento de "boas intenções", o neopopulismo se caracteriza pela administração pessoal da sociedade e pela falta de visão programática de desenvolvimento econômico e político-social, produzindo uma cultura política híbrida e passiva.

Nesse sentido, acreditamos que a cultura política é uma variável importante para entender por que o populismo tem sobrevivido na virada do milênio na América Latina.

\section{Cultura política}

As explicações de fenômenos políticos com base na cultura política ressaltam o significado do papel da história na sua configuração moderna. A opção por estudar a cultura política associada ao neopopulismo responde não só à suspeita de que tradições culturais exercem uma influência significativa (o que não significa dizer determinismo) na manutenção desse fenômeno, mas é na vigência desses tipos de governo que se materializa a base de comportamento político que auxilia a interpretar como se estrutura uma cultura política afeita ao personalismo e não às instituições. O neopopulismo é, portanto, em nossa opinião, o resultado de uma cultura política que gera formas particulares de construção de identidades. Tal reflexão se mistura a uma preocupação nos meios acadêmicos e de governos sobre o futuro da democracia nesse continente. 
Há um consenso entre os estudiosos desta temática que atualmente a democracia passa novamente por um processo de adjetivação. Entre os adjetivos modernos estão: democracia deficiente, democracia iliberal, semidemocracia, democracia eleitoral, democracia formal e democracia procedimental. Também se fala da qualidade da democracia: então por que não uma "democracia neopopulista"?

Esses tipos de democracia tomam como base a democracia representativa. O que se tenta demonstrar é que, numa democracia adjetivada na América Latina contemporânea, a proteção do cidadão pela lei e pela constituição, o mercado como instância reguladora das relações sociais e econômicas e a ilusão de paridade nas transações sociais como dimensões "modernas" são elementos que convivem simultaneamente com padrões de interação reveladores de submissão clientelística e personalista. Em outras palavras, a democracia representativa coexiste com práticas de tomada de decisões que mostram um total desprezo pelo princípio democrático. Em situações de pobreza estrutural grave e em situações de acesso desigual a informações e à educação, a igualdade formal é deslocada facilmente pelas relações patrãocliente, e as instâncias de garantia de cumprimento da lei são frequentemente violadas pelo poder de descrição das elites.

Nessa direção, Olsen (2008) argumenta que, enquanto a corrupção e a falta de representatividade continuarem a se manifestar na maioria dos países em desenvolvimento, no caso da América Latina, a situação se agravará por meio da presença da desigualdade e da pobreza. Ilustrativa do descontentamento gerado por essa situação é a resposta dos cidadãos latino-americanos que apoiariam um ditador e não um líder eleito, caso eles considerassem que um governo não democrático proporcionasse melhores benefícios econômicos (Caputo, 2004).

Assim, convive o moderno da afirmação da existência do Estado de direito com as irregularidades e atrasos nos processos penais, com a justiça de "classe", com o caos jurídico e a debilidade institucional (Schor, 2001), produzindo casos de corrupção, impunidade e arbitrariedade. Nessas circunstâncias, a maioria dos cidadãos recorre a estratégias de proteção à margem das instituições formais, pois estes não acreditam que essas instituições, formalmente responsáveis pela proteção das pessoas, o façam eficiente e eticamente.

Nesse contexto, as relações sociais se constituem em uma obrigação que deriva do afeto pessoal, pois é essa instância que recompensa, de alguma maneira, no imaginário coletivo da maioria dos latino-americanos, o fato de viverem em sociedades marcadas por profundas desigualdades e de riscos cotidianos. A consequência é de que algumas práticas se convertem em rotinas e em modus vivendi, ou em molduras funcionais que preservam práticas deletérias para a construção de uma democracia plena.

É inevitável, nesse cenário, uma realidade que não funciona nem pela dimensão moderna (novos movimentos sociais, multiculturalismo, desterritorialização e pós-modernidade), nem pela lógica não moderna, mas por uma lógica influenciada por elementos culturais que mistura o moderno com o pós-moderno. A decodificação de alguns conceitos nesse cenário, pelos cidadãos, é paradoxal, porém lógica. Por exemplo, a grande maioria das pessoas, quando indagada, afirma apoiar a democracia como valor, o que daria a ideia de que elas compreendem a dinâmica e o funcionamento de um sistema democrático. No entanto, quando indagadas sobre a operacionalidade dessa democracia que elas apoiam, a grande maioria se mostra insatisfeita e descontente. O apoio verbal não se traduz num apoio real. É o que Easton (1968) se referia como apoio difuso e apoio específico.

Este paradoxo produz uma cultura política híbrida, na qual frequentemente as coisas "funcionam" por meio de comportamentos que se desviam da moldura jurídica, da lei ou da norma, ou seja, do moderno. Dentro dessa configuração, as eleições se convertem em um protocolo vazio de competência e significado real em que predominam o personalismo e o clientelismo. Como consequência, os eleitores votam mais nas pessoas que eles acreditam poder resolver seus problemas imediatos de caráter material - como educação, saúde, trabalho e segurança - e não por preferência ou conhecimento das propostas partidárias em relação ao modelo a ser implantado, caso esses partidos sejam eleitos, e muito menos por conhecer os arranjos institucionais (Paley, 2001). Não há, portanto, bases sobre as quais identidades coletivas que emanem de um desejo de construir algo universal se materializem. Pelo contrário, reforçam-se as perspectivas individualistas e particulares. Tal fato fica claro ao se examinar o que catalisa o voto do eleitor entrevistado (Gráfico 1).

Uma das características da democracia plena, na sua dimensão política, se refere ao papel que os partidos políticos precisam desempenhar como interlocutores da sociedade perante o Estado. De um ponto de vista republicano se supõe que os partidos são centros de debate e elaboram planos de governo com os quais os eleitores aprendem a se identificar. Tal aprendizado se daria via educação política. Desse modo, estaria claro para os eleitores que os partidos possuem diferentes ideologias e essas dimensões ideológicas produziriam identidades partidárias.

Para aqueles que eventualmente não manifestam uma identificação partidária na época de eleições, essas lealdades seriam catalisadas pelas propostas dos partidos. A realidade, no entanto, mostra que 
Gráfico 1 - Quando vota o que é mais importante?

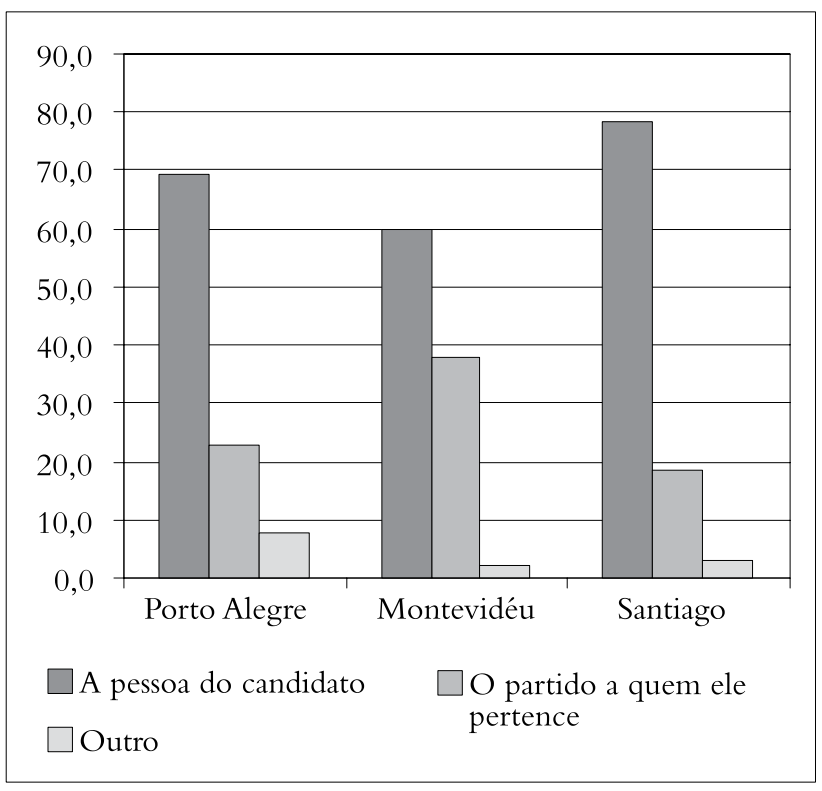

Fonte: NUPESAL, 2005. Total de entrevistados: $494 \mathrm{em}$ Porto Alegre, 415 em Montevidéu e 420 em Santiago.

esse ideal republicano está longe de se concretizar. Atualmente, os partidos abrigam nas suas fileiras os pensamentos mais diversos e contraditórios. Quase ninguém conhece os programas partidários, que frequentemente não são lidos. Os partidos de massa, por sua vez, têm se caracterizado, nos últimos anos, por ser partidos inclusivos que buscam somar vontades e, portanto, fogem de debates de natureza ideológica. Fazem promessas de todo tipo, geralmente contraditórias, mas têm um eco profundo na maioria da população que não confia nos partidos.

Esse contexto é propício para que líderes com "carisma" e com discursos afinados com o que o povo quer consigam deslocar os partidos como ponto de referência para a preferência eleitoral. A maioria dos eleitores, assim, dá muito mais importância à figura do candidato do que ao partido pelo qual ele concorre. Isto fica claramente demonstrado no Gráfico 1, no qual se observa que, em três cidades consideradas politicamente avançadas, a maioria dos entrevistados respondeu ser a pessoa do candidato o elemento fundamental para votar. Em Montevidéu, 60\% dos entrevistados, em Porto Alegre 70\%, e em Santiago do Chile, $80 \%$. Quando é o personalismo que prevalece nos pleitos eleitorais, o resultado não pode ser outro senão uma tendência ao fortalecimento do neopopulismo.

Desse modo, as relações entre democracia e neopopulismo estão sempre num processo de tensão. A democracia vê no neopopulismo um obstáculo para solidificar um marco institucional, na medida em que essa prática distorce o jogo político convencional, apelando para recursos e práticas vedadas numa concepção ampla da democracia, levando a uma desordem democrática denominada neopopulismo.

Assim, o sucesso de líderes (neo)populistas se dá em virtude da sua capacidade de mobilizar os cidadãos emocionalmente. Isto ocorre, fundamentalmente, pelo fato de que sociedades de massas, como as latino-americanas, proporcionam as bases para que as relações sociais intermediárias (com instituições políticas) não prosperem.

De maneira geral, na sociedade moderna, as relações primárias (com base na família e nas relações face a face) perdem sua função de transmitir valores de fiscalização social e de apoio psicológico. Na medida em que essas pessoas não encontram nenhum respaldo nas instituições de mediação política atuais, há uma perda de interesse delas em participar de qualquer organização formal ou informal. As relações secundárias ou intermediárias que caracterizam esse cenário são frágeis. Como resultado se consolida, a despeito dos avanços institucionais e formais, um tipo de relação social terciária na qual o cidadão estabelece uma identidade diretamente com o Estado, ou seja, com o líder político. Se esse líder político possui carisma e poder de mobilização, plasmam-se as condições para o ressurgimento do neopopulismo e de uma cultura política híbrida. Do ponto de vista da teoria democrática, tal situação produz massas urbanas, sem, no entanto, constituir cidadãos. Isto sucede porque os cidadãos não conseguem mais depender do Estado para protegê-los. Em tal cenário, as pessoas buscam fora das instituições governamentais dispositivos de proteção. Nesse caso, voltam-se fundamentalmente - e de modo paradoxal - para os líderes carismáticos de plantão.

Dessa condição resulta um cidadão politicamente vulnerável e economicamente excluído, que internaliza normas e valores de desapego às instituições de mediação política e prefere se envolver em relações de troca de favores que descaracterizam o processo democrático e, ao mesmo tempo, propicia a prosperidade do neopopulismo. A exclusão social, portanto, que se mantém na vigência das democracias modernas, produzindo uma desvinculação e insatisfação que afeta aos latino-americanos, cria um terreno fértil para os experimentos neopopulistas. Isso resulta na erosão das instituições de mediação e representação da sociedade, pois os cidadãos não participam da arena política, conforme pode ser visto no Gráfico 2.

Os dados do Gráfico 2 reúnem atividades de participação convencional, comunitária e não convencional. Embora se constatem diferenças significativas entre Montevidéu, Porto Alegre e Santiago, todas as cidades sinalizam não haver uma tradição participativa em nenhuma das modalidades examinadas. Mesmo que Montevidéu apresente os maiores índices de participação, em comparação com as outras cidades, 
Gráfico 2 - Porcentagem de cidadãos que não participam de atividades políticas

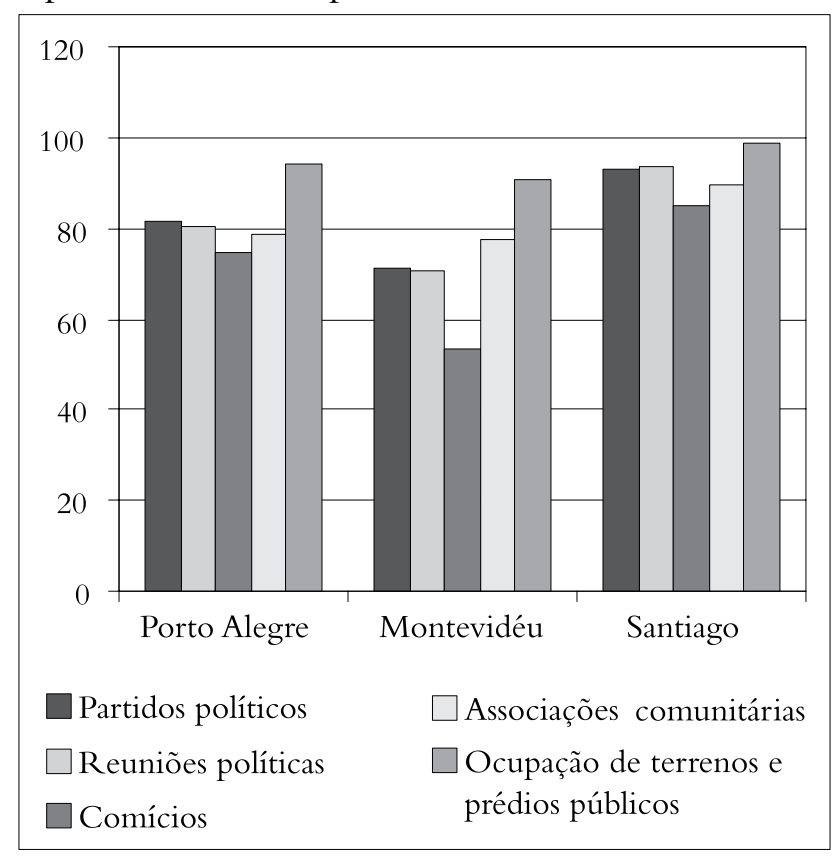

Fonte: NUPESAL, 2005. Total de entrevistados: 506 em Porto Alegre, 500 em Montevidéu e 500 em Santiago.

a percentagem dos que não participam de nenhuma atividade está acima de $60 \%$. O aspecto a ser enfatizado, nesses dados, é o desapego que os cidadãos latino-americanos mostram em relação ao envolvimento na arena política. Quando isso ocorre, a sua capacidade de se organizar torna-se frágil, e a sua participação é influenciada por iniciativas impostas com base em identificações pessoais, ou seja, vulneráveis ao neopopulismo.

Conforme referimos anteriormente, um aspecto fundamental que precariza a capacidade de organização das pessoas, propiciando a disseminação do neopopulismo, são as condições econômicas da maioria da população. A pobreza, as deficiências de acesso aos serviços de saúde, a falta de qualidade na educação e a falta de representação política constituem a regra na maioria das sociedades latino-americanas. O modo como a população avalia essas dimensões pode gerar subsídios significativos para entender com mais profundidade os fatores que catalisam as predisposições de apoio aos líderes em detrimento das instituições. Desse modo, a bateria de questões que passamos a examinar se refere ao posicionamento dos entrevistados em relação aos serviços públicos oferecidos nas suas cidades. Os dados estão no Gráfico 3.

As sociedades consideradas desenvolvidas e democráticas, segundo alguns autores (Inglehart, 1977), são aquelas que têm conseguido resolver razoavelmente a dimensão material (saúde, educação, transporte, segurança e saneamento básico). Nessas circunstâncias, essas sociedades passam a se preocu-
Gráfico 3 - Avaliação dos serviços públicos (péssimo e ruim)

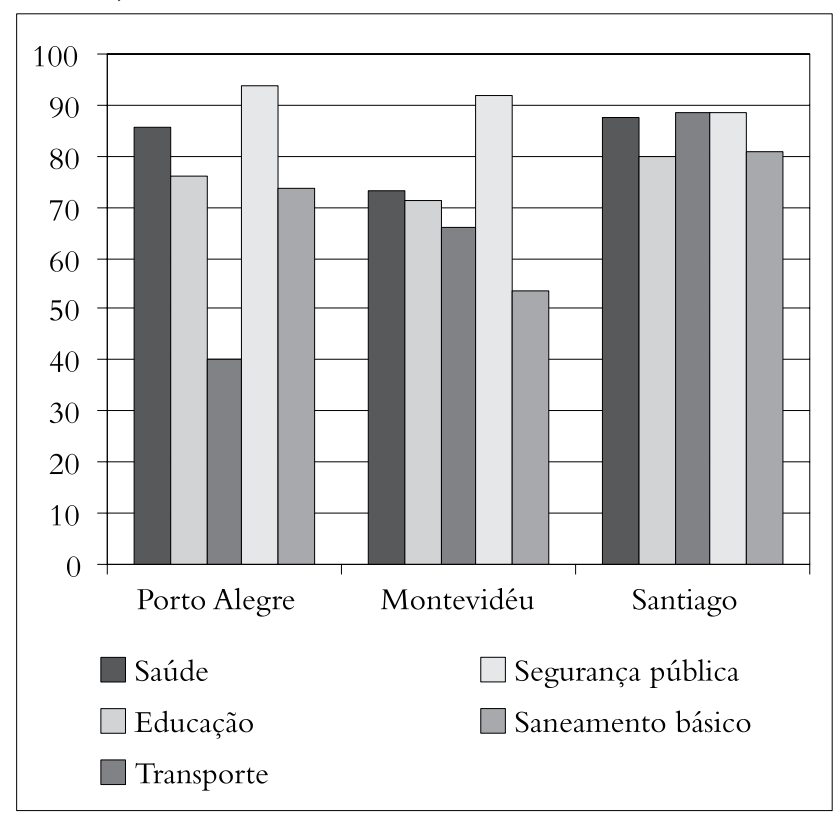

Fonte: NUPESAL, 2005. Total de entrevistados: 500 em Porto Alegre, 500 em Montevidéu e 430 em Santiago.

par com fatores pós-materialistas (qualidade de vida, cuidado com o meio ambiente e iniciativas de bemestar coletivo). Decorrente dessa situação, a dimensão política opera dentro de princípios republicanos que valorizam o jogo democrático, inibindo iniciativas políticas deletérias e de natureza pessoal. O carisma é importante, mas não é populista no sentido de manipular as instituições e os cidadãos. Nessa perspectiva, há uma associação entre qualidade de vida e ausência de iniciativas neopopulistas.

Quando a percepção dos cidadãos é a de que a dimensão material não está resolvida, as desigualdades sistemáticas geradas pela baixa qualidade de vida da maioria da população podem estar sinalizando que, a despeito dos avanços poliárquicos, existe campo fértil para iniciativas neopopulistas.

Os dados do Gráfico 3 mostram que, excetuando as categorias "transporte", em Porto Alegre, e "saneamento básico". em Montevidéu, que receberam avaliações relativamente positivas, os outros indicadores (saúde, educação e segurança) foram considerados pela ampla maioria dos entrevistados nas três cidades como ruim e péssimo (na média 76\%). Esses dados são contundentes do sentimento de desproteção que os cidadãos têm em relação ao Estado e suas instituições, o que os predispõe para discursos demagógicos e fomenta a base para iniciativas neopopulistas. 


\section{Conclusão}

A presença de um líder é importante no neopopulismo, na medida em que permite uma identificação dos cidadãos em termos emocionais. Todos os elementos simbólicos que se põem em ação com o neopopulismo estão encarnados no líder. A figura carismática é a forma que assume a liderança nas sociedades em que se quer implementar a racionalidade à vida social, desqualificando elementos-chave da própria cultura.

Trata-se de uma relação política personalizada que não é mediada por nenhuma instituição. Isso produz um discurso fragmentado, incoerente, mas que apela aos sentimentos de uma população descrente nas instituições políticas.

A esse respeito Lechner (1984, p. 28) argumentava que, nas sociedades latino-americanas, cujo sistema sociopolítico não proporciona as condições para enraizar um senso de identidade coletiva, os setores populares tentam encontrá-lo na identificação pessoal com um líder carismático.

Nesse contexto, o discurso populista exerce uma influência decisiva no desprezo que os cidadãos mostram pelas instituições convencionais de mediação política (Habermas, 1984, p. 86)

É necessário, portanto, reforçar a equidade por meio da proteção aos setores mais vulneráveis, via educação, saúde, moradia, espaço público, cultura e emprego. As lideranças que acumulam poder, gerando emprego e riqueza, não como agentes de interesses transnacionais, são agentes essenciais de desenvolvimento.
Torna-se imperativo, também, uma longa e paciente obra de reelaboração e de conversão interna da política. Essa tarefa é inadiável e inseparável da autoeducação dos cidadãos e da consequente modificação das instituições.

A natureza difusa e ambígua do "povo", do ponto de vista do neopopulismo, dificulta a organização partidária efetiva. Quer dizer, mesmo que existam partidos políticos, estes se constituem em instrumentos de "ganhar" ou "manter" o poder, sem, no entanto, ser efetivos no desempenho de sua função vital - a representação dos interesses das massas.

A precária condição social da maioria da população promove a desvinculação e insatisfação dos latino-americanos e cria um terreno fértil para experimentos neopopulistas que minam a legitimidade das instituições da democracia. Essa desvinculação tem aumentado, apesar dos avanços poliárquicos (Cepal, 2007).

Os neopopulistas habilmente capitalizam essas atitudes políticas em favor da consolidação dos seus movimentos e programas de ação governamental, visto que as predisposições hostis contra os grupos dominantes (internos e externos) colocam as classes menos favorecidas em disponibilidade política para líderes "neopopulistas carismáticos", que têm na oratória sua arma mais poderosa de persuasão.

Se aceito, pelo menos parcialmente, este argumento, pode-se concluir que o legado populista não foi a implantação de governos democráticos caracterizados por partidos políticos, mas uma nova modalidade de neopopulismo comandada pela capacidade de os líderes contemporâneos utilizarem os recursos do Estado para se manterem no poder. 


\section{Referências}

ANDRADE, Edinara T. Democracia participativa, orçamento participativo e clientelismo: um estudo. 2005. Tese (Doutorado) - Programa de Pós-Graduação em Ciência Política, Universidade Federal do Rio Grande do Sul, Porto Alegre, 2005.

CAPUTO, Dante. Democracy in Latin America: toward citizen democracy. New York: United Nations Development Program (UNDP), 2004.

CEPAL. Latin America and the Caribbean in the world economy 2006. Trends 2007. 2007. Disponível em: <http:// www.cepal.org/cgibin/getProd.asp?xml=/publicaciones/ $\mathrm{xml} / 8 / 29528 / \mathrm{P} 29528 . \mathrm{xml} \& \mathrm{xsl}=/$ comercio/tpl-i/p9f. $\mathrm{xsl} \&$ base $=/$ tpl-i/top-bottom.xslt $>$. Acesso em: 18 mar. 2010.

DAHL, Robert. Poliarquia: participação e oposição. São Paulo: Edusp, 1997.

DEBERT, Guitta. Ideologia e populismo. São Paulo: Tao, 1979.

DI TELLA, Torcuato. Para uma política latino-americana. Rio de Janeiro: Zahar, 1974.

DORNBUSCH, Rudiger; EDWARDS, Sebastian. The macro economic populism in Latin America. In:

The macro economic populism in Latin America. Chicago: Chicago University Press, 1991.

EASTON, David. Uma teoria de análise política. Rio de Janeiro: Zahar, 1968.

FALETTO, Enzo. Notas para el análisis del proceso político ecuatoriano: 1968-1978. Economía y desarrollo, v. 1, n. 6, p. 71-82, 1982.

FRANCO, Carlos; COTLER, Julio; ROCHABRÚN, Guillermo. Populismo e modernidade, Pretextos, v. 2, n. 2, fev. 1991.

GERMANI, Gino; DI TELLA, Torcuato; IANNI, Octavio. Populismo y contradicciones de classe en Latinoamérica. Mexico. Ediciones Era, 1973.

HABERMAS, Jürgen. The theory of communicative action, v. 1. Boston: Beacon Press, 1984.

HUNTINGTON, Samuel. The third wave: democratization in the late twentieth century. Norman: University of Oklahoma Press, 1991.

IONESCU, Guita; GELLNER, Ernest. Populismo: sus significados y características nacionales. Buenos Aires: Amorrortu Editores, 1970.

INGLEHART, Ronald. The silent revolution: changing values and political styles among Western publics. Princeton, NJ: Princeton University Press, 1977.

LACLAU, Ernesto. Politics and ideology in Marxist theory. London: Verso, 1977.

LECHNER, Norberto. Cultura política y democratización. David y Goliath, v. 14, n. 46, p. 21-28, 1984.

LEIS, Hector. Populismo e democracia liberal na América do Sul. Revista Debates UFRGS, v. 2, n.2, p. 25-47, 2008. LINZ, Juan; VALENZUELA, Arturo. (Orgs.). The failure of presidential democracy: comparative perspectives. London:
The John Hopkins University Press, 1994.

LITTLE, Walter. Peronism: was it an is it populist? Occasional Papers University of Glasgow, n. 20, 1975. Disponível em: <http://catalogue.nla.gov.au/Record/956422?lookfor =author:"Little,\%20Walter" $\&$ offset $=1 \& \max =1>$. Acesso em: 5 mar. 2010.

MAINWARING, Scott; SCULLY, Timothy. Building democratic institutions. California: Stanford University Press, 1995.

MENÉNDEZ-CARRIÓN, Amparo. El análisis del proceso político en el Ecuador contemporáneo: algunos comentarios a propósito de las reflexiones existentes. In: IDIS-EI, Conejo (Eds.). Estado, política e democracia en el Ecuador. Quito: Editorial El Conejo, 1988.

NUPESAL (NÚCLEO DE PESQUISAS SOBRE A AMÉRICA LATINA). Pesquisa tipo survey realizada em três cidades sul-americanas: Porto Alegre, Montevidéu e Santiago, 2005.

OLSEN, Tricia. A Latin American Paradox? Democratic quality and endurance. American Barometer Small Grant Series. 2008. Disponível em: <http://www.AmericanBarometer.org>. Acesso em: 15 abr. 2010.

PALEY, Julia. Marketing democracy: power and social movements in post-dictatorial Chile. Berkeley: University of California Press, 2001.

PLATTNER, Marc. Populism, pluralism, and liberal democracy. Journal of Democracy, v. 21, n. 1, p. 81-92, 2010.

ROBERTS, Kenneth M. Neoliberalism and the transformation of populism in Latin America. World Politics, v. 48, n. 1, p. 82-116, Oct. 1995.

ROUQUIÉ, Alain. O mistério democrático: das condições da democracia às democracias sem condições. In: ROUQUIÉ, A.; LAMOUNIER, B.; SCHVARZER, J. (Orgs.). Como renascem as democracias. São Paulo: Brasiliense, 1985.

SAES, Décio. Industrialização, populismo e classe média no Brasil. Caderno do Instituto de Filosofia e Ciências Humanas UNICAMP, n. 1, 1976.

SCHOR, Miguel. The rule of law and democratic consolidation in Latin America, 2001. Disponível em: <http://darkwing. uoregon.edu/ caguirre/schor.html>. Acesso em: 20 abr. 2010.

SMITH, Peter. The breakdown of democracy in Argentina. In: LINZ, Juan; STEPHAN, Alfred (Orgs.). The breakdown of democratic regimes. Baltimore: John Hopkins University Press, 1978.

TOCQUEVILLE, Alexis de. A democracia na América. Belo Horizonte: Itatiaia; São Paulo: Edusp, 1998.

WEBER, Max. Ciência e política: duas vocações. São Paulo: Cultrix, 1999.

WEFFORT, Francisco. O populismo na política brasileira. Rio de Janeiro: Paz e Terra, 1978.

WYNIA, Gary. The politics of latin-american development. London: Cambridge University Press, 1978. 


\title{
Populism and neo-populism in Latin America: its legacy on political parties and political culture
}

\begin{abstract}
In Latin American democracies the emergence of political phenomena regarded as extinct are now observed due to appearance of the so-called post-modern societies. One of these elements is the neo-populism, about which theoretical controversies continue to exist regarding its conceptualization and impact on the democratic process. This article aims to analyze neo-populism, evaluating its origin and evolution, its impact on political parties and the political culture that emerges if this political praxis is present. The study is of descriptive-empirical nature. The data come from a probabilistic survey conducted in three Latin American cities in 2005 . The results suggest that there are positive predispositions of citizens regarding popular political personalities and a process of discrediting of political institutions. We propose some mechanisms that could be useful to strengthen a participative political culture that makes the political leaders accountable and at the same time, could appreciate conventional mediating institutions.
\end{abstract}

Key words: neo-populism, Latin America, political parties, democracy, political culture.

\section{Populismo y neo-populismo en América Latina: su legado em los partidos políticos $y$ en la cultura política}

\section{Resumen}

En las democracias latino-americanas contemporáneas están surgiendo fenômenos que se pensava que estavan muertos, como consequência del aparecimiento de sociedades pós-modenas. Uno de eses elementos se refiere al neo-populismo, sobre el cual existen controvérsias com relación a su significado e impacto em el proceso democrático. Este articulo tiene como objetivo analizar lo nuevo en el neopopulismo, evaluando su orígen y evolución, su impacto em los partidos y en el tipo de cultura política cuando esa práxis política está presente. Este estúdio es de caráter descriptivo-empirico com base em pesquisa probabilistica realizada em 2005 em trés ciudades latino-americanas. Los resultados muestran predisposiciónes positivas de los ciudadanos com relación a lideres políticos populares em detrimiento de las instituiciónes políticas. Proponemos algunos dispositivos que poderían auxiliar a fortalecer una cultura política participativa com capacidad de fiscalización de los políticos y, al mismo tiempo, valorizando las instituiciónes de mediación política convencionales.

Palabras clave: neo-populismo, América Latina, partidos políticos, democracia, cultura política.

Data de recebimento do artigo: 6/5/2010

Data de aprovação do artigo: 4/8/2010 